\title{
Anesthetic and surgical management of patient with risk of anaphylaxis: patient safety and performance of alternative axillary brachial plexus block
}

\author{
Necip AKMAN, ${ }^{1}$ Emine Aysu SALVIZ, ${ }^{1}$ Bilge SENCAN, ${ }^{1}$ Demet ALTUN,' \\ Erol KOZANOGLU, ${ }^{2}$ Omer BERKOZ, ${ }^{2}$ Kamil Mehmet TUGRUL ${ }^{1}$
}

To the Editor,

Anaphylaxis during general anesthesia (GA) is a rare but serious event that increases catastrophic morbidity and mortality. The investigation of suspected anaphylaxis during GA is challenging as the patient is often exposed to a number of drugs within a few minutes. ${ }^{[1]}$ The large epidemiological studies in Australia ${ }^{[2]}$ and France ${ }^{[3-5]}$ demonstrated the incidence of anaphylaxis between 1/20.000-30.000 and 1/13.000. Moreover, the incidence has been estimated to be 175-1.000 reactions per annum in the United Kingdom. ${ }^{[6]}$

We would like to present a 42-year-old female patient with an American Society of Anesthesiologists (ASA) classification of 2 who had hypertension, depression, psoriasis and multiple drug allergy. She had undergone 9 operations under GA and experienced anaphylactic reactions twice culminating in internal care unit administration. Even though she was discharged upon full recovery, after a skin-prick test she was deemed allergic to propofol, meperidine, bupivacaine, cefazolin, amoxicillin-clavulanate, metronidazole, flurbiprofen, levofloxacin and diclofenac. This time, she was scheduled for tendoplasty of severe lacerations in zone two of the fourth finger of the left hand. Initially, the surgery plan was to reconstruct the deep flexor tendon injury with plantar tendon graft from the left foot. However; in this situation GA or the combination of axillary brachial plexus and sciatic nerve blocks (addition of femoral/saphenous nerve block depends on the surgical incision) were the options. None of them was seemed appropriate when the block failure with low dose, local anesthetic (LA) toxicity with high dose and anaphylaxis risks were all taken into account. Therefore, the surgical plan was altered to involve the transfer of palmaris longus tendon of the left hand (Figure 1) and the anesthesia decision was made to perform only axillary brachial plexus block under ultrasound guidance.

Two $\mathrm{mg}$ of midazolam and $50 \mathrm{mcg}$ of fentanyl were both administered intravenously (IV) in order to provide patient's sedation. The LA mixture of $10 \mathrm{~mL} 2 \%$ lidocaine $(200 \mathrm{mg}), 10 \mathrm{~mL} 2 \%$ prilocaine $(200 \mathrm{mg}$ ) and $1 \mathrm{~mL}$ adrenaline (100 $\mathrm{mcg}$ ) was prefered to avoid the recurrence of an anaphylactic reaction. Then, the high frequency linear ultrasound probe was positioned in the short axis orientation of the axilary region. Axillary artery, axillary vein, median, ulnar, radial and musculocutaneous nerves were all visualized (Figure 2). Then, $2 \mathrm{~mL}$ of $2 \%$ lidocaine was used for skin puncture. The mixture of $L A$ was administered for the block. Four $\mathrm{mL}$ was injected on top of the musculocutaneous nerve and $17 \mathrm{~mL}$ was distributed to median, ulnar and radial

\footnotetext{
'Department of Anesthesiology and Reanimation, Istanbul University Istanbul Faculty of Medicine, Istanbul, Turkey ${ }^{2}$ Department of Plastic Surgery, Division of Hand Surgery, Istanbul University Istanbul Faculty of Medicine, Istanbul, Turkey Submitted: 12.09.2014 Accepted after revision: 04.02.2015
}

Correspondence: Dr. Emine Aysu Salviz. İstanbul Üniversitesi İstanbul Tıp Fakültesi, Anesteziyoloji ve Reanimasyon Anabilim Dalı, Millet Cad., Cerrahi Monoblok Giriş Katı, 34390 İstanbul, Turkey. Tel: +90 - 212 - 5313126 e-mail: aysusalviz@gmail.com

(c) 2016 Turkish Society of Algology 

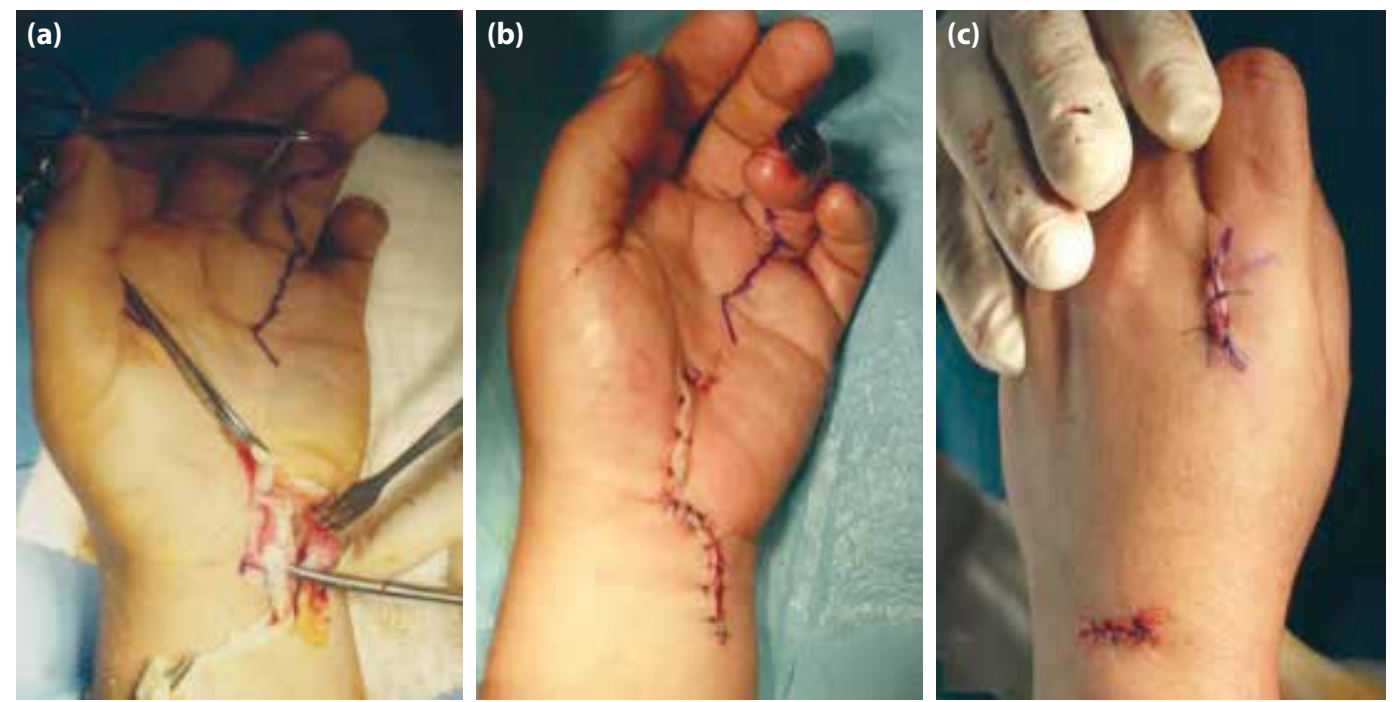

Figure 1. Reconstruction of the deep flexor tendon injury with the palmaris longus tendon of the left hand.

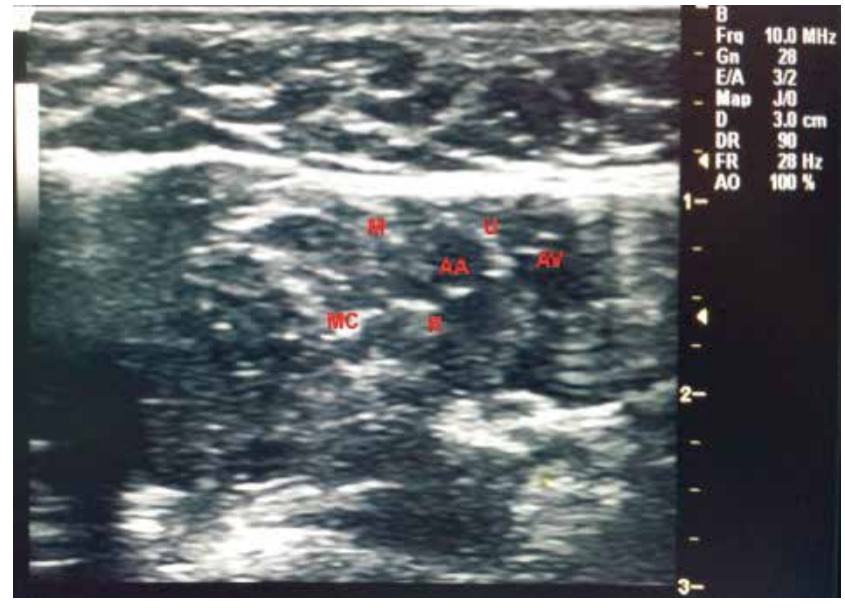

Figure 2. Ultrasound image of an axillary brachial plexus block. AA: Axillary artery; AV: Axillary vein; MC: Musculocutaneous nerve; M: Median nerve; U: Ulnar nerve; R: Radial nerve.

nerves around the axillary artery by using in-plane technique. After the adequate block, the surgery was completed uneventfully in 125 minutes. The patient was comfortable during the surgery and did not postoperatively need any supplemental analgesic until the 5 th hour $(N R S<4)$. She experienced relatively little pain, had only $500 \mathrm{mg}$ of IV paracetamol twice during the first 24 hours postoperatively (NRS $\leq 5$ ), and also described much more comfortable peroperative and postoperative periods compared to previous two similar surgeries performed on her hand under GA.

Improved anesthesia patient safety reflects doing a number of "little things" that, in the aggregate, make a big difference. ${ }^{[1]}$ Therefore; this case is presented to emphasize the importance of anesthesia and surgical team communication once more for patient safety in risky situations such as anaphylaxis and the use of alternative anesthesia techniques, especially appropriate ultrasound-guided peripheral nerve blocks (PNBs) that increases sucess rate, safety, ${ }_{1}^{[7]}$ and also decreases the morbidity and mortality of anesthesia administration.

\section{References}

1. Krishna MT, York M, Chin T, Gnanakumaran G, Heslegrave J, Derbridge $C$, et al. Multi-centre retrospective analysis of anaphylaxis during general anaesthesia in the United Kingdom: aetiology and diagnostic performance of acute serum tryptase. Clin Exp Immunol 2014;178(2):399-404.

2. Fisher M, Baldo BA. Anaphylaxis during anaesthesia: current aspects of diagnosis and prevention. Eur J Anaesthesiol 1994;11(4):263-84.

3. Mertes PM, Laxenaire MC; GERAP. Anaphylactic and anaphylactoid reactions occurring during anaesthesia in France. Seventh epidemiologic survey (January 2001-December 2002). [Article in French] Ann Fr Anesth Reanim 2004;23(12):1133-43. [Abstract]

4. Mertes PM, Laxenaire MC, Alla F; Groupe d'Etudes des Réactions Anaphylactoïdes Peranesthésiques. Anaphylactic and anaphylactoid reactions occurring during anesthesia in France in 1999-2000. Anesthesiology 2003;99(3):536-45.

5. Laxenaire MC. Epidemiology of anesthetic anaphylactoid reactions. Fourth multicenter survey (July 1994-December 1996). [Article in French] Ann Fr Anesth Reanim 1999;18(7):796-809. [Abstract]

6. Ewan PW, Dugué P, Mirakian R, Dixon TA, Harper JN, Nasser $\mathrm{SM}$; BSACl. BSACl guidelines for the investigation of suspected anaphylaxis during general anaesthesia. Clin Exp Allergy 2010;40(1):15-31.

7. Marhofer P, Harrop-Griffiths W, Willschke H, Kirchmair L. Fifteen years of ultrasound guidance in regional anaesthesia: Part 2-recent developments in block techniques. $\mathrm{Br} J \mathrm{An}$ aesth 2010;104(6):673-83. 